\title{
The neurologist's role in supporting transition to adult health care
}

\author{
A consensus statement
}

Lawrence W. Brown, MD

Peter Camfield, MD,

FRCPC

Melissa Capers, MA

Greg Cascino, MD

Mary Ciccarelli, MD

Claudio M. de Gusmao, MD

Stephen M. Downs, MD

Annette Majnemer, PhD, FCAHS

Amy Brin Miller, MSN

Christina SanInocencio, MS

Rebecca Schultz, PhD

Anne Tilton, MD

Annick Winokur, BS

Mary Zupanc, MD

Correspondence to

Dr. Brown:

brownla@email.chop.edu

Supplemental data at Neurology.org

\section{ABSTRACT}

The child neurologist has a critical role in planning and coordinating the successful transition from the pediatric to adult health care system for youth with neurologic conditions. Leadership in appropriately planning a youth's transition and in care coordination among health care, educational, vocational, and community services providers may assist in preventing gaps in care, delayed entry into the adult care system, and/or health crises for their adolescent patients. Youth whose neurologic conditions result in cognitive or physical disability and their families may need additional support during this transition, given the legal and financial considerations that may be required. Eight common principles that define the child neurologist's role in a successful transition process have been outlined by a multidisciplinary panel convened by the Child Neurology Foundation are introduced and described. The authors of this consensus statement recognize the current paucity of evidence for successful transition models and outline areas for future consideration. Neurology ${ }^{\circledR} 2016 ; 87: 835-840$

The child neurologist has a critical role in planning and coordinating the successful transition of youth with neurologic conditions from the pediatric to adult health care system. Appropriate leadership and planning of a youth's transition, and care coordination among health care, educational, vocational, and community services providers, may assist in preventing gaps in care, which otherwise may result in a youth running out of medication or delaying entry into the adult medical system through failure to make or keep appointments. Preventable health crises may develop, for which no clear medical specialist has been identified to provide care. Youth whose neurologic conditions result in cognitive or physical disability and their families may need additional support to address the particular legal and financial considerations of the transition they face.

Barriers to successful transition have been identified ${ }^{1-3}$ and ample evidence demonstrates that many youth, particularly those with special needs, continue to receive insufficient transition planning. ${ }^{4-7}$ Several models of transition support have been developed and are beginning to be tested, although the available evidence remains insufficient to identify the best models. ${ }^{5,8-12}$

In acknowledgment of this clinical reality, and in response to the 2011 clinical guideline of the American Academy of Pediatrics/American Academy of Family Physicians/American College of Physicians "supporting the healthcare transition from adolescence to adulthood in the medical home," in which specialty providers were called to develop a framework for their population's unique needs, ${ }^{13}$ the Child Neurology Foundation convened a multidisciplinary panel of experts in 2014 to develop this guideline. The authors of this consensus statement recognize the current paucity of evidence for successful transition models, and so propose 8 common principles that should be incorporated in any transition model, and which define the child neurologist's role and responsibilities throughout the transition process. Future areas of

From The Children's Hospital of Philadelphia (L.W.B.); Dalhousie University (P.C.); independent medical writer (M. Capers); Mayo Clinic (G.C.); Indiana University School of Medicine (M. Ciccarelli, S.M.D.); Brigham and Women's Hospital (C.M.d.G.); McGill University (A.M.); Child Neurology Foundation (A.B.M.); Lennox Gastaut Syndrome Foundation (C.S.); Texas Children's Hospital (R.S.); Louisiana State University Health Sciences (A.T.); patient advocate (A.W.); and Children's Hospital of Orange County (M.Z.).

An expanded version of the consensus statement, including vignettes highlighting the broad applicability of the recommendations over a variety of neurologic disorders of childhood, can be found on the Neurology ${ }^{\circledR}$ Web site at Neurology.org.

Go to Neurology.org for full disclosures. Funding information and disclosures deemed relevant by the authors, if any, are provided at the end of the article. 
consideration are also included. The consensus statement was endorsed by the American Academy of Neurology on July 28, 2015, the Child Neurology Society on May 8, 2015, and the American Academy of Pediatrics on October 21, 2015.

METHODS The Neurology Transition Consensus Panel, an interdisciplinary team including child neurologists, child neurology nurses, adult neurologists, rehabilitation specialists, patients, and family members of neurology patients, worked more than 24 months in developing the consensus statement. A medical informatician and a medical writer assisted. The medical informatician guided the panel in language choices that would facilitate the transfer of the common principles into the functionality of an electronic health record.

A member of the panel conducted a literature review of the PubMed/MEDLINE and EMBASE databases preferentially concentrated on papers published within the last 10 years and focused primarily on neurologic disorders. Older papers and book chapters that were seminal or relevant to transition in general were also included from bibliographies of the research identified in the first round search. These findings were presented to the full panel, which then discussed their interpretations of the identified research, as well as their own expert opinion. The consensus paper's findings stem from such discussions, which subsequently underwent peer review by expert external groups.

\section{COMMON PRINCIPLES}

1. The child neurology team discusses with the youth and caregiver(s) the expectation of the future transition to the adult health care system. This discussion should be initiated early and documented no later than the youth's 13th birthday.

The literature supports introducing the concept of transition as early as feasible, and no later than age $12 .{ }^{13-15}$ Early discussion allows youth and caregivers time to understand the need for transition to adult health care, and provides sufficient time for the neurology team to meet overlapping goals, such as increasing knowledge of the neurologic condition, building mastery of self-management and selfadvocacy skills, adapting to changes during puberty, and learning about developmentally appropriate models of care. ${ }^{16}$

Specific areas of concern in transition that should be introduced at this discussion include the following: anticipation of future meetings targeted at transition, private sessions between the youth and health care provider, the importance of shifting to adult providers, the differing health care needs of adults, health insurance retention, and the expectation that the youth will eventually assume responsibility for managing his or her health care needs to the extent possible.

Brochures and handouts summarizing these points may be offered to youth and caregivers. A key component of the health care transition process is the existence of an office transition policy outlining the practice's approach to health care transition, including the age and process at which youth shift to an adult model of care. ${ }^{13}$

The panel encourages the development of clear, explicit, written transition policies in brochures, handouts, and accessible Web-based information for youth and caregivers in language appropriate to the population served by the practice.

2. The child neurology team assures that an assessment of the youth's self-management skills begins at age 12 and continues on an annual basis. These assessments should be documented in the medical record and communicated to other health care providers.

Self-management of a medical condition, at a minimum, includes a youth's understanding of his or her condition and any related limitations, knowledge about and responsibility for his or her own care plan and the need to make informed decisions, and the importance of self-advocacy. A youth's eventual ability to manage his or her condition in adulthood is central to independent living and employment. Youth should be encouraged to assume responsibility commensurate with their capabilities. Research into youth capacity to consent to research and treatment suggests that these capabilities are feasible to assess by 12 years of age. ${ }^{17-19}$

Youth with intellectual disabilities should not be excluded from this process, as many may be able to develop limited self-management skills. In particular, individuals with mild intellectual disability may be able to exert some decision-making capacity, ${ }^{20,21}$ and can often become responsible for knowing their diagnosis, taking medication independently, and participating in their care.

In cases of a severe static or progressive encephalopathy in which self-management skills do not change, annual reassessment of the youth may not be as necessary. Attention to the caregivers' ability to manage evolving care demands is advisable in such cases.

A variety of checklists that evaluate self-management skills have been proposed and are in use in different transition programs, according to practice setting and conditions being treated..$^{8,22-25}$

3. The child neurology team engages each youth and his or her caregiver(s) in phased transition planning, patient education, and transfer readiness at least annually at scheduled visits, beginning at age 13 years. Yearly planning sessions address (1) the youth's medical condition; (2) current medications and potential side effects; (3) signs and symptoms of concern; (4) genetic counseling and reproductive implications of the condition; (5) issues of puberty and sexuality; (6) driving, alcohol and substance use, 
and other risks; and (7) emotional/psychological concerns and wellness.

The child neurology team continues to discuss the eventual transfer to adult health care at least annually. Ideally, these conversations are separate from regularly scheduled clinical care visits to allow for adequate time and clear expectations. ${ }^{26}$ If a dedicated transition appointment is not possible, the discussion should be held during nonacute visits. A validated assessment of transition readiness may be used to inform the discussions and planning to be engaged each year. ${ }^{22,27}$ Such a validated tool is the Transition Readiness Assessment Questionnaire. ${ }^{27}$

4. The child neurology team (1) initiates discussion by age 14 years with the caregivers regarding the youth's expected legal competency (whether there is a need for legal guardianship and powers of attorney), and (2) documents an assessment (including an assessment of typical decision-making capacity and legal competency) in the medical record. If the youth's expected legal competency is unclear, an assessment of that capacity should be made annually. The team supports interventions to maximize the youth's decision-making ability and assists the caregiver(s) in addressing the legal implications of the assessment.

Some youth with cognitive limitations will require legal guardianship and powers of attorney to be established, preferably as soon as they reach the age of majority in their state. The process of establishing legal guardianship can be expensive, complicated, and timeconsuming; in some cases, requiring as long as 2 years. By addressing the need for guardianship by, at the latest, age 14, the child neurology team can assist the youth and caregiver in coping with the reality of intellectual disability and navigating the legal system before the youth reaches the state's age of majority. Social workers, child life specialists, and other communitybased support services may be helpful throughout the guardianship process.

In cases in which expected legal competency is unclear, annual reevaluation of that capacity should be made and supported by formal psychological or neuropsychological assessment.

5. By age 14, the child neurology team assures a transition plan that meets the comprehensive needs of the youth is developed in collaboration with the youth, caregiver(s), other health care providers, school personnel, vocational professionals, community services providers, and legal services (as needed). The plan addresses health care finance and legal concerns, primary care, other specialty care, education to employment, housing, and community services. The child neurology team reviews and assures the adequacy of the transition plan annually.
Ideally, all children will have a pediatrician or family practitioner, acting as a medical home, to coordinate and maintain the comprehensive transition plan. It usually makes sense to transition from all pediatric subspecialists to adult care at the same time; this is most likely to be achieved when the various pediatric health care providers plan together. A pediatrician or family practitioner, acting as a medical home, may coordinate and maintain the comprehensive transition plan. The comprehensive transition plan should identify the youth's goals, and should clearly identify the steps necessary to achieve these goals, as well as potential barriers or obstacles to these goals, and youth and family strengths that can be built on in the process of transition. Institutional/legal transitions should be identified and their implications summarized.

The child neurology team has 3 primary responsibilities toward the comprehensive transition plan: (1) assuring that an appropriate plan exists, that it is cocreated with the youth and family, and that it is appropriately comprehensive and patient-centered; (2) identifying the professional(s) with primary responsibility for overseeing and updating the entire transition plan; and (3) providing and updating the neurologic component to this plan-including the "transfer packet" (see common principles 6 and 7, below).

Preparation of the transfer packet is the responsibility of the primary care physician or designated specialist; the transfer packet is primarily used for care coordination and communication between physicians. In addition, in the hands of the youth, the transfer packet may serve to help him or her better understand the neurologic condition and/or more efficiently communicate with other providers, whether emergency department physicians or new consultants.

6. The child neurology team develops and verifies the neurologic component of the transition plan of care and updates it annually.

The neurologic component of the transition plan should include the following: a specific summary of all health care issues; a summary of the youth's goals and preferences for adult service requirements; the planned timing of the transition to an adult provider of neurologic care (established in collaboration with the youth and caregiver); any necessary additional testing or assessments to be completed before transfer; current assessment of the youth's understanding of his or her neurologic diagnosis and management (including prognosis and any reproductive implications of the diagnosis); and emergency plans and the youth's advanced plan of care (e.g., medical power of attorney, living will, do not resuscitate order). For those with profound cognitive disability, plans for establishing guardianship are also included. 
7. The child neurology team, in collaboration with the youth and caregiver(s), identifies an appropriate adult provider(s) for the neurologic condition (s) before the anticipated time of transfer. The child neurology team coordinates the transfer utilizing the transfer packet.

One of the central challenges in the medical transition of youth with neurologic conditions is the identification of an appropriate adult provider. ${ }^{3,16,28,29}$ Barriers include adult provider's discomfort in accepting intellectually and/or behaviorally challenged youth, patients with rare childhood-onset disorders, and those with inadequate health insurance coverage. ${ }^{3}$ Some youth with neurologic conditions may be transferred to providers who are not neurologists, including primary care providers, physiatrists, and/or psychiatrists. In these cases, the child neurologist might assure the adult primary care provider of continued availability for consultation as needed. Disease-specific centers or outpatient clinics are another option for adult health care, although these tend to be available only in larger cities. $^{9}$

When an adult health care provider is identified, the child neurology team should forward a medical transfer packet that includes the transition plan and a medical summary, which should include documentation of the underlying etiology; previous drug trials, treatments, and diagnostic evaluations; notable past procedures; current medications and laboratory results; and protocol for emergency care. An updated copy of this document should be routinely provided to the youth and caregiver.

The time preceding transfer of care is fraught with high rates of anxiety by transitioning youth and their parents ${ }^{30}$; identifying an adult provider 1 to 2 years in advance of the actual transfer may help to reduce this stress. Before the actual transfer of care, successful transition models have included preliminary visits with the adult provider or joint pediatric-adult transition clinics. ${ }^{10-12,31}$ Some practices encourage the use of a transition coordinator ${ }^{11}$; adult primary care providers, especially med-peds physicians, can also serve as valuable resources during the transition process.

If an adult health care provider is not identified before the planned time or age for transfer or transfer is delayed because of extenuating circumstances such as an acute event, the child neurology team is responsible for continuing to assure the youth receives adequate care.

8. The child neurology team directly communicates with the appropriate, identified adult provider(s) to ensure that the identified provider agrees to accept the patient and an appointment is made and kept. The child neurology team documents the youth's transfer into the medical record.
The child neurology team is responsible for confirming that the transfer has been completed and adult care is established. Adult health care providers may be more open to accepting patients with neurologic conditions if they are assured of direct access to the pediatric provider should questions arise.

Note. There are some youth with neurologic disorders who are not expected to live into adulthood. Transition to an adult health care provider may not be appropriate in these unusual cases, although child neurologists may still adapt their practice with these patients to maximize skills such as self-management and independence. Conversely, some children are treated by adult neurologists; a pediatric-friendly, family-based approach should evolve to an adult model as the patients achieve maturity. In both of these cases, the common principles may help to identify areas of focus for such adaptation.

AREAS FOR FUTURE RESEARCH The literature on transition remains limited, particularly for children living with neurologic disease. The goals and optimal outcomes for transition are often not well defined, precluding objective assessments of the efficacy of transition support and/or evaluation of different models of transition support. Possible metrics for assessment include the rate of appointment completion and follow-up in the adult setting, patient and family satisfaction with transition and the new provider, stable or improved neurologic condition, adherence to care plans, decreased emergency utilization, rate of "bounce back" to pediatric providers, and improved quality of life. The extent to which these metrics might differ by patient condition, payer, geography, and other variables is also of interest.

CONCLUSION The members of the panel believe that the common principles outlined in this report are realistic, applicable to the broad spectrum of pediatric neurologic diagnoses, feasible in a wide range of practice settings, and likely to make a real difference in the lives of our patients. Subsequent development of transition toolkits and templates specific to neurology, as well as definitive research about transition for youth with neurologic disorders, will assist in implementation of these common principles.

An expanded version of the consensus statement, including vignettes highlighting the broad applicability of the recommendations over a variety of neurologic disorders of childhood, can be found on the Neurology ${ }^{\circledR}$ Web site at Neurology.org.

\section{AUTHOR CONTRIBUTIONS}

Lawrence W. Brown: drafting/revising the manuscript, study concept or design, analysis or interpretation of data, accepts responsibility for conduct of research and will give final approval, study supervision. Peter R. Camfield: drafting/revising the manuscript, study concept or design, 
analysis or interpretation of data, accepts responsibility for conduct of research and will give final approval. Melissa Capers: drafting/revising the manuscript, accepts responsibility for conduct of research and will give final approval. Greg Cascino: drafting/revising the manuscript, study concept or design, analysis or interpretation of data, accepts responsibility for conduct of research and will give final approval, acquisition of data. Mary Ciccarelli: drafting/revising the manuscript, study concept or design, analysis or interpretation of data, accepts responsibility for conduct of research and will give final approval. Claudio de Gusmao: drafting/revising the manuscript, analysis or interpretation of data, accepts responsibility for conduct of research and will give final approval, acquisition of data, performed literature review. Stephen Downs: drafting/ revising the manuscript, study concept or design, analysis or interpretation of data, accepts responsibility for conduct of research and will give final approval. Annette Majnemer: drafting/revising the manuscript, study concept or design, analysis or interpretation of data, accepts responsibility for conduct of research and will give final approval. Amy Brin Miller: drafting/revising the manuscript, accepts responsibility for conduct of research and will give final approval. Christina SanInocencio: drafting/revising the manuscript, accepts responsibility for conduct of research and will give final approval. Rebecca Schultz: drafting/revising the manuscript, accepts responsibility for conduct of research and will give final approval. Anne Tilton: drafting/revising the manuscript, study concept or design, accepts responsibility for conduct of research and will give final approval. Annick Winokur: drafting/revising the manuscript, accepts responsibility for conduct of research and will give final approval. Mary Zupanc: drafting/revising the manuscript, accepts responsibility for conduct of research and will give final approval, study supervision.

\section{ACKNOWLEDGMENT}

The authors thank the following professional and advocacy organizations for serving as reviewers: American Academy of Cerebral Palsy and Developmental Medicine, American Academy of Child \& Adolescent Psychiatry, American Academy of Neurology, American Academy of Pediatrics, Association of Child Neurology Nurses, Child Neurology Society, Epilepsy Foundation of America, Family Voices, Lennox-Gastaut Syndrome Foundation, National Association of Pediatric Nurse Practitioners, National Organization for Rare Disorders, Society for Adolescent Health \& Medicine, Society of General Internal Medicine Transition Task Force, and Tuberous Sclerosis Alliance.

\section{STUDY FUNDING}

This project was funded in part by a sponsorship from Eisai Inc. All content was solely developed by Child Neurology Foundation's expert author panel.

\section{DISCLOSURE}

L. Brown reports no disclosures relevant to the manuscript. P. Camfield has received a speakers honorarium from Biocodex. M. Capers reports no disclosures relevant to the manuscript. G. Cascino serves as associate editor for Neurology ${ }^{\circledR}$, is an investigator in the Human Epilepsy Project, receives technology royalties from Mayo Medical Ventures (high frequency nerve stimulation to treat lower back pain, Nervo), and receives honoraria from the American Academy of Neurology and American Epilepsy Society. M. Ciccarelli, C. de Gusmao, S. Downs, A. Majnemer, and A. Miller report no disclosures relevant to the manuscript. C. SanInocencio served as a consultant for Eisai Inc.'s Living with LGS Web site and educational video, and serves as a consultant for Lundbeck's LGS Workgroup. R. Schultz has no disclosures relevant to this manuscript. Dr. Schultz receives royalties from UpToDate on the topic of Rett Syndrome and salary support from HRSA grant 13-244, State and Regional Approaches to Improving Access to Services for Children and Youth with Epilepsy. A. Tilton is a consultant for Ipsen pharmaceuticals. Dr. Tilton administers botulinum toxin in her clinical practice (35\% effort). Dr. Tilton has a patent in conjunction with LSUHSC on the use of botulinum toxin in refractory acne. There are royalties associated with the patent through LSUHSC. A. Winokur and M. Zupanc report no disclosures relevant to the manuscript. Go to Neurology.org for full disclosures.

Received December 14, 2015. Accepted in final form May 17, 2016.

\section{REFERENCES}

1. Lariviere-Bastien D, Bell E, Majnemer A, Shevell M, Racine E. Perspectives of young adults with cerebral palsy on transitioning from pediatric to adult healthcare systems. Semin Pediatr Neurol 2013;20:154-159.

2. Cheak-Zamora N, Farmer J, Mayfield W, et al. Health care transition services for youth with autism spectrum disorders. Rehabil Psychol 2014;59:340-348.

3. Oskoui M, Wolfson C. Treatment comfort of adult neurologists in childhood onset conditions. Can J Neurol Sci 2012;39:202-205.

4. McManus MA, Pollack LR, Cooley WC, et al. Current status of transition preparation among youth with special needs in the United States. Pediatrics 2013;131:1090-1097.

5. Woodward JF, Swigonski NL, Ciccarelli MR. Assessing the health, functional characteristics, and health needs of youth attending a noncategorical transition support program. J Adolesc Health 2012;51:272-278.

6. Bindels-de Heus K, van Staa A, van Vliet I, Ewals FV, Hilberink SR. Transferring young people with profound intellectual and multiple disabilities from pediatric to adult medical care: parents' experiences and recommendations. Intellect Dev Disabil 2013;51:176-189.

7. Shogren KA, Plotner AJ. Transition planning for students with intellectual disability, autism, or other disabilities: data from the National Longitudinal Transition Study2. Intellect Dev Disabil 2012;50:16-30.

8. Jurasek L, Ray L, Quigley D. Development and implementation of an adolescent epilepsy transition clinic. J Neurosci Nurs 2010;42:181-189.

9. Van Lierde A, Menni F, Bedeschi MF, et al. Healthcare transition in patients with rare genetic disorders with and without developmental disability: neurofibromatosis 1 and Williams-Beuren syndrome. Am J Med Genet A 2013; 161A:1666-1674.

10. Rutishauser C, Sawyer SM, Ambresin AE. Transition of young people with chronic conditions: a cross-sectional study of patient perceptions before and after transfer from pediatric to adult health care. Eur J Pediatr 2014;173: 1067-1074.

11. Annunziato RA, Baisley MC, Arrato N, et al. Strangers headed to a strange land? A pilot study of using a transition coordinator to improve transfer from pediatric to adult services. J Pediatr 2013;163:1628-1633.

12. Carrizosa J, An I, Appleton R, Camfield P, Von Moers A. Models for transition clinics. Epilepsia 2014;55(suppl 3): 46-51.

13. Cooley WC, Sagerman PJ. Supporting the health care transition from adolescence to adulthood in the medical home. Pediatrics 2011;128:182-200.

14. Robb A, Findling RL. Challenges in the transition of care for adolescents with attention-deficit/hyperactivity disorder. Postgrad Med 2013;125:131-140.

15. Lemly DC, Weitzman ER, O'Hare K. Advancing healthcare transitions in the medical home: Tools for providers, families and adolescents with special healthcare needs. Curr Opin Pediatr 2013;25:439-446.

16. Reiss JG, Gibson RW, Walker LR. Health care transition: youth, family, and provider perspectives. Pediatrics 2005; 115:112-120.

17. Hein IM, Troost PW, Lindeboom R, de Vries MC, Zwaan CM, Lindauer RJL. Assessing children's competence to consent in research by a standardized tool: a validity study. BMC Pediatr 2012;12:156. 
18. Bolt I, van Summeren MJH. Competence assessment in minors, illustrated by the case of bariatric surgery for morbidly obese children. Best Pract Res Clin Gastroenterol 2014;28:293-302.

19. Hein IM, Troost PW, Lindeboom R, et al. Accuracy of the MacArthur Competence Assessment Tool for Clinical Research (MacCAT-CR) for measuring children's competence to consent to clinical research. JAMA Pediatr 2014; 168:1147-1153.

20. Wong JG, Clare CH, Holland AJ, Watson PC, Gunn M. The capacity of people with a "mental disability" to make a health care decision. Psychol Med 2000;30:295-306.

21. Suto WM, Clare CH, Holland AJ, Watson PC. Capacity to make financial decisions among people with mild intellectual disabilities. J Intellect Disabil Res 2005;49:199-209.

22. Sawicki GS, Lukens-bull K, Yin X, et al. Measuring the transition readiness of youth with special healthcare needs: validation of the TRAQ_-Transition Readiness Assessment Questionnaire. J Pediatr Psychol 2011;36:160-171.

23. Moynihan M, Saewyc E, Whitehouse S, Paone M, McPherson G. Assessing readiness for transition from paediatric to adult health care: revision and psychometric evaluation of the Am I ON TRAC for Adult Care questionnaire. J Adv Nurs 2015;71:1324-1335.

24. Schrans DG, Abbott D, Peay HL, et al. Transition in Duchenne muscular dystrophy: an expert meeting report and description of transition needs in an emergent patient population. Neuromuscul Disord 2013;23:283-286.

25. Camfield CS, Berg A, Stephani U, Wirrell EC. Transition issues for benign epilepsy with centrotemporal spikes, nonlesional focal epilepsy in otherwise normal children, childhood absence epilepsy, and juvenile myoclonic epilepsy. Epilepsia 2014;55(suppl 3):16-20.

26. Davies H, Rennick J, Majnemer A. Transition from pediatric to adult health care for young adults with neurological disorders: parental perspectives. Can J Neurosci Nurs 2011;33:32-39.

27. Wood DL, Sawicki GS, Miller MD, et al. The Transition Readiness Assessment Questionnaire (TRAQ): its factor structure, reliability, and validity. Acad Pediatr 2014;14:415-422.

28. Brown LW, Roach ES. Outgrowing the child neurologist: facing the challenges of transition. JAMA Neurol 2013;70: 496-497.

29. Nabbout R, Camfield P. Bringing the transition of epilepsy care from children to adults out of the shadows. Epilepsia 2014;55(suppl 3):52-53.

30. Bloom SR, Kuhlthau K, Van Cleave J, Knapp AA, Newacheck P, Perrin JM. Health care transition for youth with special health care needs. J Adolesc Health 2012;51:213-219.

31. Camfield P, Camfield C. Transition to adult care for children with chronic neurological disorders. Ann Neurol 2011;69:437-444. 


\section{Neurology}

\section{The neurologist's role in supporting transition to adult health care: A consensus statement}

Lawrence W. Brown, Peter Camfield, Melissa Capers, et al.

Neurology 2016;87;835-840 Published Online before print July 27, 2016

DOI 10.1212/WNL.0000000000002965

This information is current as of July 27, 2016

\section{Updated Information \& Services}

Supplementary Material

\section{References}

Citations

Subspecialty Collections

Permissions \& Licensing

Reprints including high resolution figures, can be found at: http://n.neurology.org/content/87/8/835.full

Supplementary material can be found at: http://n.neurology.org/content/suppl/2016/07/27/WNL.0000000000002 965.DC1

This article cites 31 articles, 0 of which you can access for free at: http://n.neurology.org/content/87/8/835.full\#ref-list-1

This article has been cited by 1 HighWire-hosted articles: http://n.neurology.org/content/87/8/835.full\#\#otherarticles

This article, along with others on similar topics, appears in the following collection(s):

All Clinical Neurology

http://n.neurology.org/cgi/collection/all_clinical_neurology

All Practice Management

http://n.neurology.org/cgi/collection/all_practice_management Models of care

http://n.neurology.org/cgi/collection/models_of_care

Information about reproducing this article in parts (figures,tables) or in its entirety can be found online at:

http://www.neurology.org/about/about_the_journal\#permissions

Information about ordering reprints can be found online:

http://n.neurology.org/subscribers/advertise

Neurology ${ }^{\circledR}$ is the official journal of the American Academy of Neurology. Published continuously since 1951, it is now a weekly with 48 issues per year. Copyright @ 2016 American Academy of Neurology. All rights reserved. Print ISSN: 0028-3878. Online ISSN: 1526-632X.

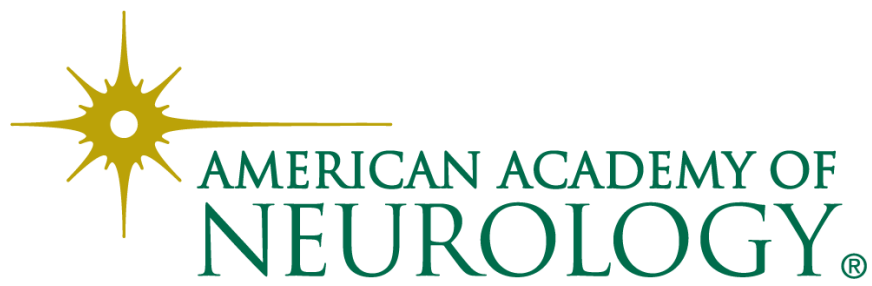

